\title{
A Rural Household Heating Method that Combines a Regenerative Electric Boiler with PV Power Generation
}

\author{
Caiqing Zhang, Guoshuai Gao* \\ School of Economic and Management, North China Electric Power University, Baoding, China
}

Received: 11 April 2018

Accepted: 16 September 2018

\begin{abstract}
The heating mode of a regenerative electric boiler in China's rural area includes many problems such as the increase of heating cost, the high expense of government subsidies and tr investment cost, etc. Consequently, this paper proposes a new heating method that combines a regenerative electric boiler with distributed photo-voltaic power generation. The photovoltaic software PVsyst was used to simulate generating capacity, and a system-wide economic efficiency calculation model was established. Taking a family in Gaobeidian City as an example, a comparative analysis of the method before and after optimization was conducted. The results showed that the new heating method has good economics, environmental benefits and promotional value. This new rural household heating method is of great significance for realizing the rural household energy cleanness in the Beijing-Tianjin-Hebei metropolitan region, promoting the green and low-carbon development of rural energy, and realizing beautiful rural construction.
\end{abstract}

Keywords: rural household heating method; regenerative electric boiler; photovoltaic power generation

\section{Introduction}

For quite a long time, the energy consumption of China has been dominated by coal, which brought severe pollution to the environment [1]. The Beijing-TianjinHebei metropolitan region is one of the most heavily polluted areas in China, with much higher occurrence of severe haze in winter of this region than in the other three seasons [2]. A large amount of pollutants from heating emissions in winter is a significant factor, contributing

*e-mail: 839863960@qq.com to serious haze phenomenon [3]. The reduction of coal utilization has therefore become a common goal for the government dedicated to addressing air pollution on a national scale.

The government has attached great importance to rural energy development as a strategic issue, because it has a bearing on the smooth implementation of major strategic layouts such as the construction of a well-off society and new rural construction. The green and lowcarbon development of rural energy plays a vital role in the implementation of the rural revitalization strategy, which in turn promotes the energy revolution. The report of the $19^{\text {th }}$ National People's Congress suggests 
that the country must adhere to giving priority to developing agriculture and rural areas, and accelerate the modernization of agriculture and rural areas, and firmly take the path of developing civilization and creating a good living environment for people.

In order to improve clean energy utilization in rural areas and reduce air pollution caused by coal combustion in winter, the government has put forward an implementation plan for replacing coal with electricity in recent years and advocating for people to use electric heating equipment such as regenerative electric boilers for heating. In addition, the state has also issued a series of related industrial policies, subsidy policies, and beneficial agricultural policies in the rural energy sector, which promoted the rapid development of rural energy and provide an energy guarantee for building a well-to-do society. As of the end of September 2017, the "Replacing Coal by Electricity" project has completed 1.75 million households and renovated 5763 villages in the BeijingTianjin-Hebei region. The heating area has exceeded 100 million square meters [4].

However, the subsidies of electricity fees and the investment in heating equipment puts great pressure on the government. Moreover, the construction and transformation of a power grid needs a large investment, which is difficult for power grid enterprises to undertake. With the tremendously increasing electricity consumption in rural areas caused by the large power of the regenerative electric boiler, the government has implemented a peak-valley electricity price policy in many places, and also subsidized electricity prices. These policies have reduced electricity bills, whereas they have made electricity consumption peak in rural areas shift from summer to winter, and concentrate at low-load periods, thus disenabling the rural distribution grids being used to bear the burden. Therefore, it is of great significance to explore new heating methods, make full use of renewable energy, and actively develop distributed power generation.

As the most abundant renewable energy, solar energy has the advantages of non-pollution, easy access and so on, with great potential for development. In addition, distributed photovoltaic power generation in accordance with the principles of local grid connection not only meet the specific requirements of power system and users, but can also improve the flexibility, reliability and economy of the system.

There is abundant literature on distributed generation and electrical energy for heating methods. Some research has focused on replacing coal by electricity and distributed generation. These include, but are not limited to, comprehensive energy evaluation, potential analysis, integrated energy system, smart grid and distribution network transformation, and so on [5-10]. Other literature has concentrated on the storage and scheduling of distributed generation, the evaluation of solar energy for household heating, the utilization of solar PV system in the residential buildings and a comparison of heat supply for various alternative energy sources, etc. [11-17]. However, few studies have explored the combination of distributed generation and electric heating.

In order to make full use of abundant solar energy resources, improve energy consumption structure in rural areas, increase the proportion of self-use renewable energy and promote the smooth implementation of replacing coal by electricity projects, this study proposed optimizing the heating mode of a regenerative electric boiler by using distributed photovoltaic power generation. Through the simulation of a family photovoltaic system in Hebei Province, the systems economic benefit before and after optimization was compared and analyzed, which sheds new light on optimizing electric heating methods.

\section{Materials and Methods}

\section{Optimization Principle}

A regenerative electric boiler is an efficient, safe and pollution-free electric heating system that utilizes the low-cost electricity at night to heat the medium stored in the electric heating device in order to realize the process of converting electric energy into heat energy. The medium dissipates heat energy to a warm room.

The way of a "roof-distributed PV system + regenerative electric boiler" can optimize the current heating mode. In other words, the photovoltaic system and distribution network are both used as power supply for a regenerative electric boiler. As the primary power supplier, the photovoltaic array provides electricity for a heating system when solar radiation is sufficient. When solar radiation is low, cheap electricity at night provides most power for the heating system, whose heat can meet heating demand. During the non-heating period, all the electricity generated by the photovoltaic system is used to connect to the grid, which can also get revenue from selling electricity while receiving national subsidies.

This article carried out power generation simulation in order to achieve the optimal design of the heating method of the thermal storage electric boiler with PVsyst6.6.6, which has been developed by researchers at Geneva University and is mainly used to model and simulate photovoltaic power generation systems, analyze various factors affecting power generation, and ultimately calculate power generation. It is widely used in the field of photovoltaic system design in China.

The installation inclination angle of the module, the distance between the front and back rows, and the installation quantity are determined by the location information of the photovoltaic project such as longitude and latitude and the roof orientation of the photovoltaic system. The radiation received on the slope 
of the photovoltaic module would reach maximum by adjusting these parameters throughout the year.

\section{Software Design}

The information of altitude, longitude and latitude of PV installation site were input into PVsyst software to establish location information. An appropriate meteorological database was selected to ensure the accuracy of simulated electricity generation.

Considering temperature as one of the important factors affecting the power generation efficiency of modules, the rooftop photovoltaic systems generally adopted a fixed installation method to ensure air circulation. According to the location of the building and the type of roof, we chose the appropriate installation orientation, angle and optimal spacing of components to guarantee maximum solar radiation throughout the year. The next step was to select the appropriate photovoltaic module and determine the arrangement mode, number, and installed capacity of the photovoltaic array string on the basis of roof size. The final step was simulating power generation via the software.

\section{Calculating the Economic Benefit} of the System before Optimization

The energy consumption of a regenerative electric boiler in the annual heating season can be conducted as follows:

$$
E_{0}=P_{0} \cdot H \cdot d
$$

...where $E_{0}$ represents the energy consumption of the regenerative electric boiler in the annual heating season $(\mathrm{kWh}) ; P_{0}$ indicates the rated power of the regenerative electric boiler $(\mathrm{kW}) ; H$ denotes the daily operating time (h), and $d$ is the number of days during the heating season.

Due to the purchase cost of equipment borne by the government, the equipment purchase and maintenance cost were not in consideration. The heating cost of the regenerative electric boiler system $C$ can be expressed by Eq. (2):

$$
C= \begin{cases}\left(\mathrm{p}_{1}-\mathrm{r}_{1}\right) \cdot E_{0} & E_{0} \leq \mathrm{m} \\ \mathrm{p}_{1} \cdot E_{0}-\mathrm{m} \cdot \mathrm{r}_{1} & E_{0}>\mathrm{m}\end{cases}
$$

...where $\mathrm{p}_{1}$ is the low-load tariff of residents' heating (yuan/kWh), $r_{1}$ indicates the electricity price subsidy of household heating (yuan/kWh), and $\mathrm{m}$ represents the upper limit of the subsidized electricity quantity in the heating season $(\mathrm{kWh})$.
Calculating the Economic Benefit of the System after Optimization

\section{System Economic Income during Non-Heating Period}

The laboratory data predicted that the maximum service life of a photovoltaic system can be up to 25 years. Due to less recovery of photovoltaic equipment, the operating time of a photovoltaic system was assumed to be 20 years in this paper.

If all the electricity generated by the roof photovoltaic system is grid-connected during the non-heating period, economic income $I_{1}$ can be expressed in Eq. (3):

$$
I_{1}= \begin{cases}E_{1} \cdot\left(\mathrm{p}_{2}+\mathrm{r}_{2}+\mathrm{r}_{3}\right) & t \leq 3 \\ E_{1} \cdot\left(\mathrm{p}_{2}+\mathrm{r}_{2}\right) & 3<t \leq 20\end{cases}
$$

...where $E_{1}$ denotes the generated energy from the non-heating photovoltaic system $(\mathrm{kWh}) ; \mathrm{p}_{2}$ indicates the feed-in tariff (yuan/kWh); $r_{2}$ represents the national subsidy for each kilowatt hour of photovoltaic power (yuan/kWh); $r_{3}$ is the provincial subsidy for each kilowatt hour of photovoltaic power, the period of subsidy being 3 years (yuan $/ \mathrm{kWh}$ ); and $t$ indicates the number of years for the user to install the photovoltaic system (years).

\section{System Economic Income during Heating Period}

During the heating period, the electricity generated by the roof photovoltaic system is entirely used for the regenerative electric boiler, then the economic income $I_{2}$ of the users in this period is mainly the subsidy for generating electricity, which is described as:

$$
I_{2}= \begin{cases}E_{2} \cdot\left(\mathrm{r}_{2}+\mathrm{r}_{3}\right) & t \leq 3 \\ E_{2} \cdot\left(\mathrm{r}_{2}\right) & 3<t \leq 20\end{cases}
$$

...where $E_{2}$ indicates the amount of electricity generated by the roof photovoltaic power system during the heating period $(\mathrm{kWh})$.

\section{Optimized System Cost}

The costs of the optimized system mainly include the construction cost of the rooftop photovoltaic system $C_{1}$ and the electricity consumption of the regenerative electric boiler during the off-peak period $C_{2}$, which can be expressed in Eq. (5) and Eq. (6) respectively:

$$
C_{1}=P^{\prime} \cdot \mathrm{q}_{0}
$$




$$
C_{2}=\mathrm{p}_{1} \cdot E_{3}
$$

...where $P^{\prime}$ means the installed capacity of a PV system $(\mathrm{kW}) ; q_{0}$ denotes the price of each installed $1 \mathrm{~kW}$ photovoltaic system (yuan $/ \mathrm{kW}$ ); and $E_{3}$ indicates the energy consumption of the regenerative electric boiler during the off-peak time $(\mathrm{kW})$, which can be expressed using Eq. (7):

$$
E_{3}=E_{0}-E_{2}
$$

\section{Investment Payback Period}

This article evaluated the economic performance of the optimized system according to investment payback period. The dynamic investment payback period $P_{\mathrm{t}}$ could be described with the following equation:

$$
P_{\mathrm{t}}=T-1+\left[\frac{\sum_{t=1}^{T-1}\left(I_{1}+I_{2} \ddot{*} C_{1}-C_{2}\right)_{t}}{\left(I_{1}+I_{2} \ddot{*} C_{1}-C_{2}\right)_{t}}\right]
$$

...where $T$ represents the number of years during which the present value of cumulative net cash flow is positive (years).

\section{Calculating Environmental Benefits of the System}

Due to complex components involved in the system and no component-related energy consumption parameters, the environmental cost of the system was not considered in this paper. Therefore, the environmental benefits of the system mainly equal pollutant emission reductions compared with those before optimization.

This article adopts the standard coal equivalent coefficient of thermal power generation in the China Energy Statistical Yearbook: $0.4040 \mathrm{Kg}$ standard coal $/ \mathrm{kWh}$. The pollutant emission reductions $C_{\text {oal }}$ can be described as:

$$
C_{\text {oal }}=0.4040 \cdot E_{2}
$$

The annual pollutant emission reduction $V$ of the regenerative electric boiler before optimization $(t)$ and management $\operatorname{cost} F$ saved by the emission reduction (yuan) could be described as follows:

$$
V=C_{\text {oal }} \sum_{i=1}^{4} \gamma_{i} / 1000
$$

$$
F=C_{\text {oal }} \sum_{i=1}^{4} \gamma_{i} \cdot P_{i} / 1000
$$

Here $\gamma_{\mathrm{i}}(\mathrm{i}=1-4)$ indicates the emission coefficients of $\mathrm{CO}_{2}, \mathrm{SO}_{2}, \mathrm{NO}_{\mathrm{x}}$ and dust; $\mathrm{P}_{\mathrm{t}}$ represents the environmental cost of the corresponding pollutants (yuan/t).

\section{Results and Discussion}

This article takes a family in the village of Xinglongtun within Gaobeidian city limits in Hebei Province as an example. There are 5 people in this family with a heating area of about $100 \mathrm{~m}^{2}$, and the rated power of the thermal storage electric boiler used is $12 \mathrm{~kW}$. Through operation for 8 hours during the off-peak period to store energy, it can achieve the purpose of all-day heating, high-efficiency, energysaving and environmental protection.

The latitude, longitude and altitude of the case are $115.85^{\circ}, 39.33^{\circ}$ and $34 \mathrm{~m}$, respectively. The location information was established by inputting this information into the PVsyst software. Considering the data of solar radiation in the Meteonorm database closer to the actual statistical data than the NASA database [18], we chose the historical meteorological information in the Meteonorm7.1 database in order to predict PV generation. In general, when the photovoltaic array in the Northern Hemisphere faces toward the south, power generation can reach the highest value [19]. So the installation orientation of the battery panels should be toward the south at

\begin{tabular}{|c|c|}
\hline \multicolumn{2}{|l|}{ Specification } \\
\hline Peak power/W & 275 \\
\hline Power tolerance/W & $0 /+3$ \\
\hline Battery chip size/mm & $1640 * 992 * 35 \mathrm{~mm}$ \\
\hline $\begin{array}{l}\text { Maximum power point operating } \\
\text { voltage/V }\end{array}$ & 31.20 \\
\hline Peak power current/A & 8.82 \\
\hline Open circuit voltage/V & 38.7 \\
\hline Short-circuit current/A & 9.26 \\
\hline Component efficiency & 16.80 \\
\hline Power tolerance/W & 275 \\
\hline \multicolumn{2}{|c|}{$\begin{array}{l}\text { Note: Standard test conditions: air quality AM1.5, irradiance } \\
1000 \mathrm{~W} / \mathrm{m}^{2} \text {, battery temperature } 25^{\circ} \mathrm{C}\end{array}$} \\
\hline
\end{tabular}
an installation angle of $36^{\circ}$ according to PVsyst calculation.

In order to ensure that the photovoltaic panels are not occluded from 9 a.m. to 3 p.m., the optimal distance

Table 1. Detailed parameters of the PV components. 
Table 2. Average monthly day-hour power generation situation of the PV system in heating season (kWh).

\begin{tabular}{|c|c|c|c|c|c|c|c|c|c|c|c|c|c|}
\hline $\begin{array}{c}\text { Month } \\
\text { Time }\end{array}$ & $7 \mathrm{H}$ & $8 \mathrm{H}$ & $9 \mathrm{H}$ & $10 \mathrm{H}$ & $11 \mathrm{H}$ & $12 \mathrm{H}$ & $13 \mathrm{H}$ & $14 \mathrm{H}$ & $15 \mathrm{H}$ & $16 \mathrm{H}$ & $17 \mathrm{H}$ & $18 \mathrm{H}$ & $\begin{array}{c}\text { Power } \\
\text { generation }\end{array}$ \\
\hline January & 0.00 & 1.58 & 3.76 & 5.39 & 6.15 & 6.48 & 6.15 & 5.14 & 3.39 & 1.19 & 0.00 & 0.00 & 1216.13 \\
\hline February & 0.13 & 2.43 & 4.66 & 6.25 & 7.12 & 7.27 & 7.32 & 6.31 & 4.36 & 2.16 & 0.15 & 0.00 & 1396.64 \\
\hline March & 1.12 & 3.13 & 4.92 & 6.00 & 6.96 & 7.03 & 7.22 & 6.20 & 4.82 & 2.75 & 0.85 & 0.01 & 765.15 \\
\hline November & 0.30 & 2.25 & 4.23 & 5.25 & 6.03 & 6.09 & 5.74 & 4.27 & 2.59 & 0.51 & 0.00 & 0.00 & 558.90 \\
\hline December & 0.00 & 1.60 & 3.38 & 5.05 & 5.83 & 5.73 & 5.75 & 4.63 & 2.23 & 0.06 & 0.00 & 0.00 & 1062.06 \\
\hline Total & 1.55 & 10.99 & 20.95 & 27.94 & 32.09 & 32.60 & 32.18 & 26.55 & 17.39 & 6.67 & 1.00 & 0.00 & 4998.88 \\
\hline
\end{tabular}

between the front and rear distance is $4 \mathrm{~m}$. In this case, the components are arranged in 4 rows and 10 pieces per row for the sake of giving full play to roof resources and meeting the use requirements of electric heat storage boiler. The total installed capacity is $13.20 \mathrm{~kW}$.

A single crystal silicon module was used in the case, of which specific performance parameters of the photovoltaic module are shown in Table 1. Table 2 shows the average daily hourly power generation of the photovoltaic system every month during the heating period, from which we can know that the system generates electricity from 7 a.m. to 5 p.m. Table 3 indicates the average daily hourly power generation of the photovoltaic system every month during the non-heating period, from which we can know that the system generates electricity from 5 a.m. to 6 p.m. The non-heating period is from 16 March to 15 November.

Assuming that February is 29 days, then $d$ is 121 days. The values of other variables are shown in Table 4.

\section{Analysis of System Economic Benefit before Optimization}

As calculated in Eq. (1) and Eq. (2), electricity consumption $E_{0}$ for heating in the whole winter is $11616 \mathrm{kWh}$ and the heating cost $C$ of the family is 1484.80 yuan/year. If the heating area is calculated as $100 \mathrm{~m}^{2}$, the unit heating cost of the family is 14.85 yuan $/ \mathrm{m}^{2 *}$ year.

Table 3. Average monthly day-hour power generation situation of the PV system in non-heating season (kWh).

\begin{tabular}{|c|c|c|c|c|c|c|c|c|c|c|}
\hline Month & March & April & May & June & July & August & September & October & November & Total \\
\hline $5 \mathrm{H}$ & 0.00 & 0.00 & 0.08 & 0.24 & 0.05 & 0.00 & 0.00 & 0.00 & 0.00 & 0.37 \\
\hline $6 \mathrm{H}$ & 0.00 & 0.39 & 0.81 & 0.85 & 0.64 & 0.4 & 0.18 & 0.00 & 0.00 & 3.27 \\
\hline $7 \mathrm{H}$ & 1.12 & 2.02 & 2.46 & 2.23 & 1.92 & 1.67 & 1.56 & 1.18 & 0.30 & 14.46 \\
\hline $8 \mathrm{H}$ & 3.13 & 3.99 & 4.33 & 3.81 & 3.34 & 3.06 & 3.16 & 2.90 & 2.25 & 29.97 \\
\hline $9 \mathrm{H}$ & 4.92 & 5.42 & 5.91 & 5.14 & 4.44 & 4.41 & 4.77 & 4.15 & 4.23 & 43.39 \\
\hline $10 \mathrm{H}$ & 6.00 & 6.95 & 6.97 & 5.99 & 5.30 & 5.32 & 5.90 & 5.37 & 5.25 & 53.05 \\
\hline $11 \mathrm{H}$ & 6.96 & 7.35 & 7.20 & 5.91 & 5.64 & 5.32 & 6.33 & 6.04 & 6.03 & 56.78 \\
\hline $12 \mathrm{H}$ & 7.03 & 7.32 & 6.95 & 6.09 & 5.76 & 5.48 & 6.78 & 6.16 & 6.09 & 57.66 \\
\hline $13 \mathrm{H}$ & 7.22 & 7.18 & 6.43 & 5.85 & 5.35 & 5.06 & 6.28 & 5.38 & 5.74 & 54.49 \\
\hline $14 \mathrm{H}$ & 6.2 & 6.11 & 5.42 & 5.18 & 4.88 & 4.48 & 5.38 & 4.34 & 4.27 & 46.26 \\
\hline $15 \mathrm{H}$ & 4.82 & 4.60 & 4.42 & 4.07 & 3.97 & 3.53 & 3.68 & 2.98 & 2.59 & 34.66 \\
\hline $16 \mathrm{H}$ & 2.75 & 2.90 & 2.91 & 2.76 & 2.86 & 2.26 & 2.19 & 1.32 & 0.51 & 20.46 \\
\hline $17 \mathrm{H}$ & 0.85 & 1.14 & 1.32 & 1.35 & 1.44 & 1.18 & 0.71 & 0.03 & 0.00 & 8.02 \\
\hline $18 \mathrm{H}$ & 0.01 & 0.09 & 0.33 & 0.46 & 0.48 & 0.24 & 0.01 & 0.00 & 0.00 & 1.62 \\
\hline $19 \mathrm{H}$ & 0.00 & 0.00 & 0.00 & 0.00 & 0.01 & 0.00 & 0.00 & 0.00 & 0.00 & 0.01 \\
\hline Power generation & 816.16 & 1663.80 & 1721.74 & 1497.90 & 1428.48 & 1314.71 & 1407.90 & 1235.35 & 558.90 & 11644.94 \\
\hline
\end{tabular}


Table 4. Value of every variable.

\begin{tabular}{|c|c|c|c|}
\hline Variable & Value & Variable & Value \\
\hline$P_{0} / \mathrm{kW}$ & 12 & $\mathrm{p}_{2} / \mathrm{yuan} \cdot \mathrm{kWh}^{-1}$ & 0.3644 \\
\hline$P^{\prime} / \mathrm{kW}$ & 13.2 & $\mathrm{r}_{1} /$ yuan $\cdot \mathrm{kWh}^{-1}$ & 0.20 \\
\hline $\mathrm{H} /$ hours & 8 & $\mathrm{r}_{2} / \mathrm{yuan} \cdot \mathrm{kWh}^{-1}$ & 0.42 \\
\hline $\mathrm{m} / \mathrm{kWh}$ & 10000 & $\mathrm{r}_{3} /$ yuan $\cdot \mathrm{kWh}^{-1}$ & 0.20 \\
\hline $\mathrm{p}_{1} /$ yuan $\cdot \mathrm{kWh}^{-1}$ & 0.30 & $\mathrm{q}_{0} / \mathrm{yuan} \cdot \mathrm{kW}^{-1}$ & 7000 \\
\hline
\end{tabular}

Table 5. Sensitivity analysis of investment payback period.

\begin{tabular}{|c|c|c|c|c|}
\hline $\begin{array}{c}\text { Electricity price } \\
\text { subsidy/yuan } \cdot \mathrm{kWh}^{-1}\end{array}$ & 0 & 0.1 & 0.15 & 0.2 \\
\hline Payback period/year & 8.91 & 8.04 & 7.67 & 7.33 \\
\hline
\end{tabular}

Table 6. Emissions of standard coal pollutants and environmental costs [21].

\begin{tabular}{|c|c|c|c|c|}
\hline The pollutants & $\mathrm{CO}_{2}$ & $\mathrm{SO}_{2}$ & $\mathrm{NO}_{x}$ & Dust \\
\hline$\gamma_{i} / \mathrm{t} \cdot t c e^{-1}$ & 1.731 & 0.022 & 0.010 & 0.017 \\
\hline$P /$ yuan & 92 & 6000 & 8000 & 2200 \\
\hline
\end{tabular}

\section{Analysis of System Economic Benefit after Optimization}

As indicated in Tables 1 and 2, power generation $E_{1}$ is $11644.94 \mathrm{kWh}$, and power generation $E_{2}$ is $4998.88 \mathrm{kWh}$. Electricity consumption $E_{3}$ is $6617.12 \mathrm{kWh}$, calculated based on Eq. (7).

Supposing that $t$ is 20 years. According to Eq. (3) and Eq. (4), the economic income $I_{1}$ of the user in the non-heating period is 10881.03 yuan/year over the last 3 years, and the economic income $I_{2}$ during the heating period is 2849.36 yuan/year. In the next 4-20 years, economic income $I_{1}$ in the non-heating period will be 8552.04 yuan per year, and economic income $I_{2}$ will be 1849.59 yuan/year.

From Eq. (5) and Eq. (6), the construction cost $C_{1}$ of the rooftop PV system is 92,400 yuan and $C_{1}$ is 1985.14 yuan/year. As calculated by Formula (8), the investment payback period of the optimized system is 8.91 years. The general benchmark investment recovery period in this industry is 15 years. We generally think that if the payback period is less than 15 years, the PV project will be feasible [20].
The economic benefits of the system are greatly affected by policies. This paper takes the electricity price subsidy as the variable to study its influence on the investment recovery period of the optimized heating mode. The calculated results are shown in Table 4.

As seen in Table 5, the investment recovery period is shortened with the increase of electricity price subsidies, which indicates that the electricity price subsidy can effectively shorten the investment recovery period and improve economic benefits.

\section{Environmental Benefit Analysis}

The pollutant emission of standard coal combustion per unit and the corresponding environmental costs are shown in Table 5.

According to Formula (9), the electric energy saved by the optimized system during the heating period is equivalent to 2.020 tons of standard coal. The environmental benefits of the system are shown in Table 7, which are calculated by Table 6, Eq. (10) and Eq. (11).

Table 7 shows that the emission reduction of pollutants during the heating period is 3.596 tons per year and the environmental treatment cost saved by the system is 825.477 yuan per year, which shows that the optimized system has good environmental benefits.

\section{Conclusions}

In order to solve the problem of replacing coal by electricity in rural areas of the Beijing-Tianjin-Hebei region, this paper optimized the heating mode of a regenerative electric boiler, and conducted the simulation design with a household as a typical case by adopting the distributed photovoltaic power generation. Through economic benefit analysis, the new heating method has not only decreased the heating cost and saved the governmental electricity subsidy of 2,000 yuan for users' heating, but also produced good environmental benefits and enabled residents to get certain income each year.

This is a new heating method for integrating the distributed photovoltaic system with electric heating proposed under the current background of replacing coal by electricity. With preferential utilization of renewable resources as the basic principle, the multienergy complementary approach has been adopted to realize the cleanliness of rural life heating and solve the problem of bulk coal substitution. This research

Table 7. Environmental benefit of the optimized system during the heating period.

\begin{tabular}{|c|c|c|c|c|c|}
\hline The pollutants & $\mathrm{CO}_{2}$ & $\mathrm{SO}_{2}$ & $\mathrm{NO}_{\mathrm{x}}$ & Dust & Total \\
\hline Emission reduction/t & 3.497 & 0.044 & 0.020 & 0.034 & 3.596 \\
\hline Environmental value/yuan & 321.689 & 266.64 & 161.6 & 75.548 & 825.477 \\
\hline
\end{tabular}


has not only reduced the user's heating costs and alleviated the pressure of power grid load and power grid transformation investment and construction, but also could relieve the electricity price subsidies of the state. Our study is of great significance for major strategic deployments such as the implementation of clean energy in rural life, the promotion of developing green and low-carbon energy in rural areas, and the implementation of beautiful rural construction, thus it is worth popularizing.

In order to promote the widespread use of distributed photovoltaic power generation, the following suggestions are proposed in this paper:

- The original subsidy for a distributed PV system for electric heating mode should be maintained in order to mobilize residents' enthusiasm to install rooftop photovoltaic power generation systems.

- We should perfect the carbon trading system and incorporate household-distributed photovoltaics into the carbon trading market in order to increase residents' income through carbon trading.

- The government should encourage and promote the business model of PV loan, and encourage photovoltaic operators to cooperate with banks so that residents can be provided with the initial construction fund in order to solve the problem of insufficient initial investment in photovoltaic power generation systems.

- Third-party investment companies should be encouraged to develop and utilize roofing resources in an entire villages, townships and even larger areas. Residents can rent or use rooftop resources as inputs to participate in interest distribution. The PV system can be constructed to integrate electricity into local power grids, and in turn the electricity can be sold to users in order to achieve win-win results.

- It is necessary to encourage rural residents to improve household heat preservation and reduce electricity consumption during the heating period by using thermal inertia energy stored in houses.

\section{References}

1. XIONG WEI, FU ZONGPING, WANG PENG Discussion on the promotion of the reform of rural energy supply side under the construction of ecological environment, Rural Economy, 12, 94, 2017.

2. MA XIAOQIAN, LIU ZHENG, ZHAO XUYANG, TIAN LIHUI, WANG TONG The Spatial and Temporal Variation of Haze and Its Relativity in the Beijing-TianjinHebei Region. Areal Research and Development, 35 (2), 134, 2016.

3. LE HUI, LI HAOYUE, JIANG YI The Air Source Heat Pump replace The Heating Stove for Rural Residential Heating and adjust Power Peak Load at the same time. Energy of China, 38 (11), 9, 2016.

4. LV YINLING "Coal to Electricity" promoted by the State Grid significant effect. China Energy News, 021, 2017.

5. ZHANG ZHENYU, YANG GUOHUA, CHE CHAO, ZHAO WENQUN Study of economic and environmental benefits analysis of roof photovoltaic system. Electric Power Environmental Protection, 32 (4), 53, 2016.

6. LI RUI Comprehensive Benefit Evaluation Method of Distributed Generation Micro grid Projects Based on Different Business Models. Power System Technology, 41 (06), 1748, 2017.

7. HEI CHENYANG, GUAN YUANPENG, XIE YUNXIANG, ZHU XIMENG Simulation analysis of distribution network with distributed photovoltaic generation system based on Thevenin-Norton equivalence. Electric Power Automation Equipment, 37 (10), 71, 2017.

8. CHENG LIN, ZHANG JING, HUANG RENLE, WANG CUNPING, TIAN HAO Case analysis of multi-scenario planning based on multi-energy complementation for integrated energy system. Electric Power Automation Equipment, 37 (06), 282, 2017.

9. ZENG BO, LI YINGZI, LIU ZONGQI, FENG JIAHUAN, ZHANG JIANHUA Comprehensive Evaluation Method for Environmental Benefits of Smart Distribution Network Based on TO-PCA. Power System Technology, 40 (02), 396, 2016.

10. GONG XIAOXU, JIN QIANG, WANG JI, SHI ZINAN, MA WEIJING Effects of Distributed PV Connected to Grid on Distribution Network Constructions in Typical Functional Zones. Electric Power, 49 (03), 166, 2016.

11. SARDI J., MITHULANANTHAN N., HUNG D.Q. Strategic allocation of community energy storage in a residential system with rooftop PV units. Applied Energy, 206, 159, 2017.

12. BABACAN O., RATNAM E.L., DISFANI V.R., KLEISSL J. Distributed energy storage system scheduling considering tariff structure, energy arbitrage and solar PV penetration. Appl. Energy, 205, 1384, 2017.

13. FISCHER D., BERNHARDT J., MADANI H., WITTWER C., YAN J. Comparison of control approaches for variable speed air source heat pumps considering time variable electricity prices and PV. Appl. Energy, 204, 93, 2017.

14. WHEELER K.A., ELSAMAHY M., FARIED S.O. A Novel Reclosing Scheme for Mitigation of Distributed Generation Effects on Overcurrent Protection. IEEE Trans. Power Delivery, 99, 1, 2017.

15. FIEDUCIK J., GODLEWSKI J. Storing Thermal Energy from Solar Collectors for the Needs of a Detached House. Polish J. Environ. Studies, 23 (4), 1373, 2014.

16. ABD-UR-REHMAN H.M., AL-SULAIMAN F.A., MEHMOOD A., SHAKIR S., UMER M. The potential of energy savings and the prospects of cleaner energy production by solar energy integration in the residential buildings of Saudi Arabia. J. Clean. Pro. 183, 2018.

17. REDLARSKI G., PIECHOCKI J., DABKOWSKI M. Reducing air pollutant emissions from the residential sector by switching to alternative energy sources in singlefamily homes. Polish J. Environ. Studies, 22 (1), 197, 2013.

18. LI YINGZI, LI ZHI Comparison and Selection of Solar Radiation Data for Photovoltaic Power Generation Projects. Building Electr. 35 (04), 35, 2016.

19. ROBAA S.M. A study of ultraviolet solar radiation at Cairo urban area, Egypt. Solar Energy, 77 (2), 251, 2004.

20. JIANG FUPING The Study of Comprehensive benefit evaluation in PV generationproject. Hubei Univer. of Technol. 2016.

21. ZHU QUNZHI, LEI SISI, JIANG TINGYAN Economical and environmental analysis of building photovoltaic systems with different installation styles. Acta Energy Solar Sinica, 33 (01), 24, 2012. 